\title{
Automated Irrigation and Smart Farming
}

\author{
S. Sri Heera, P Suganthan, S Sudarshan Athreya, S Suriya Narasimman, M Rakesh
}

\begin{abstract}
Industry 4.0 has already arrived in the world and is leaving no stone unturned. It can be quickly summarized into just 4 components being, Cyber- physical systems, IOT, Cloud Computing and Cognitive computing. Current technologies, which uses soil moisture sensor require hard wiring and manual interventions. Other timer technologies irrigate the plants at certain interval without checking the need. In the proposed system, robotics with Artificial Intelligence are integrated with IoT systems to allow the farmer who is available at a different location than the farm to get the necessary updates involving the irrigation process taking place in the field. The system will also drain the excess water. The proposed system would allow better water management, higher yield and reduce the required manpower.
\end{abstract}

Keywords: Artificial Intelligence, Automated Irrigation, IoT.

\section{INTRODUCTION}

Agriculture was the most basic and primitive industry known to man. Establishment of agriculture paved the way for the beginning of human civilization. Agriculture is having the largest workforce of about $60 \%$, but its contribution to the GDP is just $20 \%$ roughly. In Spite of low contribution, this sector is very important as this ensures the survival of every person. In agriculture, irrigation is the most time consuming and delicate process. So proper care should be taken to supply optimal amount of water to the crops without wastage. According to the latest NITI AAYOG report, cultivation techniques are the reason for the drought like conditions. Though the process would be expensive, it would producefruitful results in the future. The project incorporates the latest buzz words like Artificial Intelligence, Data Science and Internet of Things into creating robots that can work on agricultural fields. The robot will collect real-time moisture data from the soil and send the collected data to a control system. Here the data is analysed and the decision to send water to the region is made. This process is done to all the regions in the field ensuring all the parts get the required amount of water. In times of excess water there may arise a requirement to drain the water from the field which can be done with the drainage canal. Water from the field can be directed to recharge the ground water by letting it into the bore well after 7 layers of filtration. The seven-layer filter will ensure that only clean water is recharged back into the ground.

Revised Manuscript Received on 14 August, 2019. Engineering, Easwari Engineering College, Chennai, Tamil Nadu, India.

P Suganthan, UG Student, Department of Computer Science Engineering, Easwari Engineering College, Chennai, Tamil Nadu, India.

S SudarshanAthreya, UG Student, Department of Computer Science

S SuriyaNarasimman, UG Student, Department of Computer Science Engineering, Easwari Engineering College, Chennai, Tamil Nadu, India

M Rakesh, UG Student, Department of Computer Science Engineering, Easwari Engineering College, Chennai, Tamil Nadu, India.
S. Sri Heera, Assistant Professor, Department of Computer Science Engineering, Easwari Engineering College, Chennai, Tamil Nadu, India.

\section{EXISTING TECHNOLOGY}

Smart irrigation which began from 1980's is trying to cut down on manual labour and improvethe yield with the help of new technologies available such as: -

a. Soil Moisture Sensors Used With Smart Irrigation ControllersSoil moisture sensor-based smart irrigation controllers use one of several well-established technologies to measure soil moisture content. When buried in the root zone of turf, trees or shrubs, the sensors accurately determine the moisture level in the soil and transmit this reading to the controller. Here are two different soil moisture sensor-based systems available:

b. Suspended Cycle Irrigation Systems, which are set like traditional timer controllers, with watering schedules, start times and duration. The difference is that the system will stop the next scheduled irrigation when there is enough moisture in the soil.

c. Water On Demand Irrigationrequires no programming of irrigation duration (only start times and days of the week to water). It has a user-set lower and upper threshold, which initiates irrigation when the soil moisture level fails to meet those levels.

\section{PROPOSED SYSTEM}

The main aim of the system is to reduce the amount of excess water each part of the field receives due to manual irrigation. The system makes use of pipelines that are connected to the field via a raspberry pi centre which would automatically turn on or off the water supply to the field. The parameter for deciding when to allow water is determined by the amount of moisture currently present in the soil at an instant. This value is recorded by a robot that constantly moves around the field checking the moisture content in the soil for the designated regions. The robot is also fitted with the necessary sensors for transmitting the data to the raspberry pi. The shape of the robot is similar to an insect. This allows it to move better on the soil without its legs getting stuck in the soil.

This value is sent to the raspberry pi and water is sent to the area if the moisture is low. LoRa(Long Range communication) Transmitter is used to transmit real time data(moisture, GPS) to the raspberry pi. The extent of network connectivity ranges over a radius of $5 \mathrm{~km}$ which would essentially cover the entire field. In case of a large field we can use multiple robots to scan the field and check for the moisture content in the area. Raspberry pi is connected to the outputs of the e-rain gauge system, to get real time data about the rain levels in the place. Incase of heavy rains the irrigation need not be done for a period of time, which is calculated based on rain levels. If there

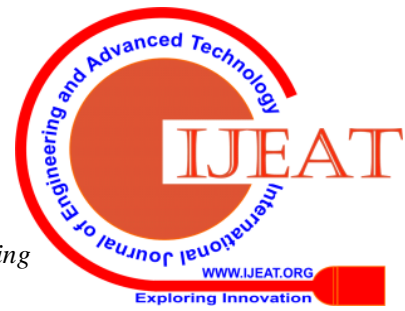


occurs water stagnation due to rain, they are measured using sensor and the excess water is drained to the groundwater using natural water way systems.

\section{ARCHITECTURE\& RESULTS}

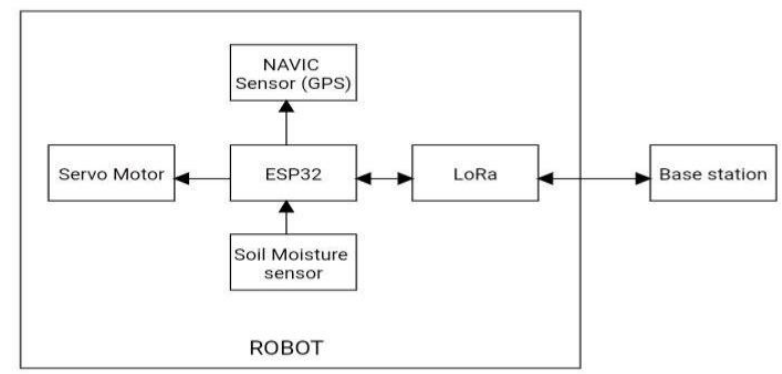

Fig 1 Real Time Data Collector

In fig. 1 the ESP32 is the brain of the system. It is used to control the servo motor for the precise movement and NAVIC sensor is used to get the location details accurately, LoRa is a transmitting and receiving module which has a range of $5 \mathrm{~km}$ Automated Irrigation and SmartFarming

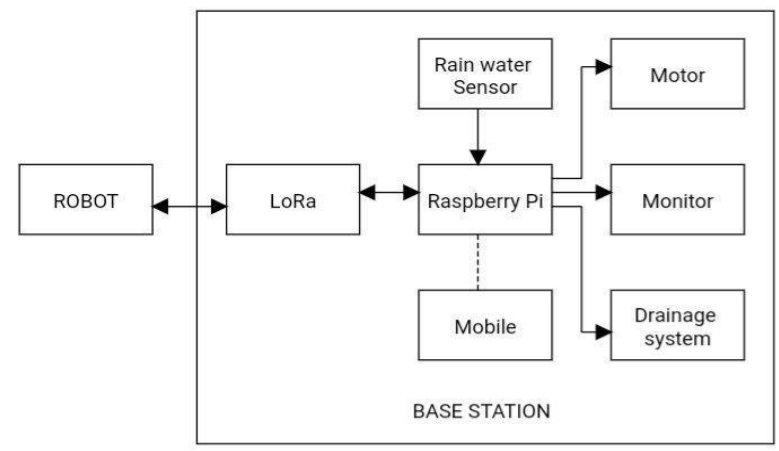

Fig 2 Base station

In fig 2 the raspberry pi is the brain and it is connected to rain water sensor, humidity sensor. It regulates the flow of water by controlling the pumps in the field and in case of a flood the drainage system is used to remove the excess water to underground.

\section{LITERATURE SOURCES}

Mrs.T.Vineela,,J.NagaHarini,„Ch.Kiranmai, G.Harshitha and B.AdiLakshmi, proposed IoT Based Agriculture Monitoring and Smart Irrigation System Using Raspberry $\mathrm{Pi}$, in which they use soil moisture sensor which should be embedded in the soil at continuous intervals. It relays the real time data to the Raspberry Pi. It is highly inefficient since a lot of sensors are required and since the soil structure changes as the plants grow, sensors will be disturbed.

Joaquín Gutiérrez, Juan Francisco Villa-Medina, Alejandra Nieto-Garibay, and MiguelÁngelPortaGándara Proposed Automated Irrigation System Using a Wireless Sensor Network and GPRS module. Sensors are powered by solar power to sense the soil moisture content and send them to the base station. Solar power systems eliminate the need for the laying wires inside the field. There may occur power disruption when plants grow, and the costs of solar panels are high. Use of GPRS is unreliable as there may occur network loss and GPRS charges are recurring.
Q. Wang, A. Terzis and A. Szalay, proposed A Novel Soil Measuring Wireless Sensor Network, in which communication between the sensors are based on the relays that are present on top of the soil. The communication between the relays is 50 meters at maximum and communication between sensor and relay are 0.4 meter at maximum. It enables the fully wireless communication. In this form of communication there is a requirement to use large number of relays to transfer the data from sensor to the Raspberry Pi. If a relay at start is damaged, the data from sensors might not reach the base.

Venkata Naga RohitGunturi proposed Micro Controller Based Automatic Plant Irrigation System in which the Data received from the sensors are used to operate the irrigation system as per the requirement. This system can be easily implemented, and the costs are less. The data in this system is not used for any analytics or for optimized water distribution in future.

\section{CONCLUSION}

Use of Robotics and artificial intelligence can increase the yield of crops, along with reduction the labour work and optimal usage of water. This will in turn increase the profit of the farmer, and also help the farmer to attend other works without compromising the field work. The farmer can also attend the emergencies in the field as he will be updated about the irrigation activities in real time.

Using the robot generates huge profits for the farmer. There is a significant increase to gains and a decrease in the amount spent. Generally, every person working in the field is paid Rs.400 per day for the irrigation activities. Also, irrigation is done on alternate days. Therefore, the farmer would have to pay the workers around Rs.12000 per crop cycle per person. This cost would only be higher as the number of people involved increases. Therefore, by using the robot the farmer can cut down on these expenses and get good profit by investing less.

\section{REFERENCES}

1. Chetan Dwarkani M, Ganesh Ram R, Jagannathan S, R Priyatharshini "Smart agriculture system using sensors for agricultural task automation," in 2015 IEEE International Conference on Technological Innovations in ICT for Agriculture and Rural Development (TIAR2015).

2. Dr. V .Vidya Devi,G. Meena Kumari, "Real- Time Automation and Monitoring System for Modernized Agriculture" ,International Journal of Review and Research in Applied Sciences and Engineering Vol3 No.1. PP 7-12,2013.

3. I. Mampentzidou, E. Karapistoli, A.A. Economide, "BasicGuidelines for Deploying Wireless Sensor Networks in Agriculture", Fourth International Workshop on Mobile Computing and Networking Technologies, pp.864-869,2012.

4. Joaquín Gutiérrez, Juan Francisco Villa-Medina, Alejandra Nieto-Garibay, and MiguelÁngel Porta Gándara" Automated Irrigation System Using a Wireless Sensor Network and GPRS module", Ieee Transactions On Instrumentation And Measurement, Vol. 63, No. 1,2014 . 
5. Mrs.T.Vineela, J. NagaHarini, Ch.Kiranmai, G.Harshitha, B.AdiLakshmi, "IoT Based Agriculture Monitoring and Smart Irrigation System Using Raspberry $\mathrm{Pi}$,'International Research Journal of Engineering and Technology (IRJET)e-ISSN: 2395-0056 Vol. 05 Issue: 01,2018

6. Nikesh Gondchwar, R. S. Kawitkar, "IOT based smart agriculture,'International Journal Of Advanced research in computer and Communication Engineering (IJARCCE), vol. 5, no. 6,2016.

7. Q. Wang, A. Terzis and A. Szalay, "A Novel Soil Measuring Wireless Sensor Network", IEEE Transactions on Instrumentation and Measurement, pp.412-415,2010

8. Tejas Bangera, Akshar Chauhan, Harsh Dedhia, Ritesh Godambe, Manoj Mishra, "IOT based smart village," International Journal of Engineering Trends and Technology, vol. 32, no. 6,2016.

9. Venkata Naga Rohit Gunturi, "Micro Controller Based Automatic Plant Irrigation System" International Journal of Advancements in Research \& Technology, Volume 2, Issue- 4,2013.

\section{AUTHORS PROFILE}

S.SRI HEERA working as Assistant professor in Easwari engineering college, Chennai. She received her B.E from DhanalashmiSrinivasan College of Engineering and Technology in the year 2014, M.E degree from St.Joseph's College of Engineering in the year 2016. She
s. and her area of specialization is Big data, has 3 years teach

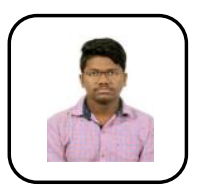

\section{P SUGANTHAN}

Pursuing B.E at Easwari Engineering College doing my 3rd year in the department of Computer Science and Engineering I am interested in the latest technologies like IOT and Hardware Designing.

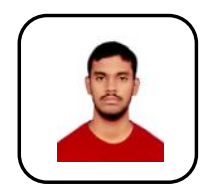

\section{S SUDARSHAN ATHREYA}

Pursuing B.E at Easwari Engineering College Currently doing my 3rd year in the department of Computer Science and Engineering I am really interested in the latest technologies like Artificial Intelligence and Machine Learning.

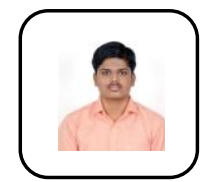

\section{S SURIYA NARASIMMAN}

Pursuing B.E at Easwari Engineering College doing my 3rd year in the department of Computer Science and Engineering I am interested in the latest technologies like Data Science, IOT and Web Development.

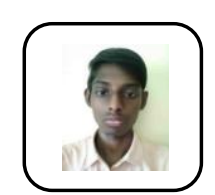

\section{RAKESH}

Pursuing B.E at Easwari Engineering College doing my 3rd year in the department of Computer Science and Engineering I am interested in the latest technologies like Machine Learning and IOT.

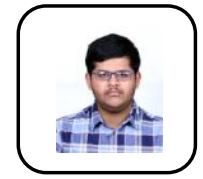

\section{RAHUL}

Currently pursuing UG B.E degree in CSE branch in Easwari Engineering College.I show great promise in the fields of Artificial Intelligence, Internet of Things and Data Science. 